\title{
BOOK AND MEDIA REVIEWS
}

\section{COVID-19 and World Order: The Future of Conflict, Competition, and Cooperation}

Edited by Hal Brands and Francis J. Gavin

Johns Hopkins University Press, Baltimore, 2020, 472 pp., \$29.95 paperback

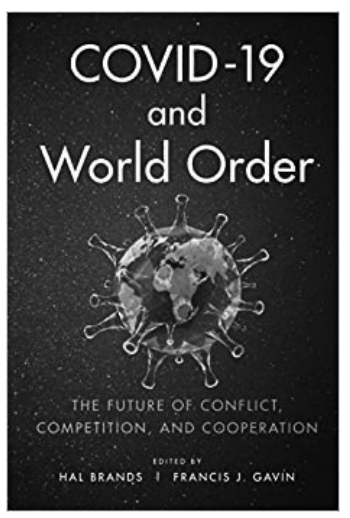

COVID-19 and World

Order is a collec-

tion of essays edited by Hal Brands and Francis J. Gavin from the Johns Hopkins University School of Advanced International Studies and the Henry A. Kissinger Center for Global Affairs, respectively, with their colleagues from similar institutes and think tanks.

The book is organized into seven parts: Applied History and Future Scenarios; Global Public Health and Mitigation Strategies; Transnational Issues; Technology, Climate, and Food; Future of the Global Economy; Global Politics and Governance; Grand Strategy and American Statecraft; Sino-American Rivalry.

The instigating and unifying theme of the book is the pandemic and how it will affect all our lives going forward. It likens the impact of the pandemic in historical scope and rapidity to the two major world wars in the past century. I found this opening section a compelling comparison. Those wars shook the foundations of civilization, nations, commerce, diplomacy, and reordered the world.

Such a reordering is now taking place. While it does, we must make sure our health care systems including our public health programs are fully prepared and reinvented.

Perhaps most salient to practicing and teaching family doctors is the identification of the weaknesses of our public health systems worldwide. If we fail to recognize and respond to these issues, from problems in nursing homes to food supply to the environment, we will have missed a major opportunity to improve the health of our planet.
Dr Lainie Rutkow, author of the chapter, "Origins of the COVID-19 Pandemic and the Path Forward: A Global Public Health Policy Perspective" attests that public health is an "invisible discipline." 1 This is a striking statement as public health measures from sanitation, safe food and water supplies, widespread immunization programs, smoking cessation campaigns, and containment of epidemics like AIDS, SARs, malaria, cholera, yellow fever, tuberculosis, and many more have lengthened both quality and quantity of life throughout the world.

Perhaps we have become lackadaisical and take these advances as a given, as part of our infrastructure. Such advances in public health have created enormous impacts, extending life expectancy and reducing infant mortality globally over the last century. In so doing, perhaps we have unwittingly created the very overpopulation that has set the stage for future pandemics. Resultant environmental disruption, zoonosis, and viral spillovers will likely continue.

Only when the infrastructure fails do we take notice. The COVID crisis points to the fault lines and vulnerabilities of public health measures locally, nationally, and internationally. According to several authors in the book, the failures of the World Health Organization, overly influenced by financial support and political pressure from China, delayed the announcement of the Wuhan person-to-person infection for critical weeks while it spread globally by international travel.

Former Centers for Disease Control and Prevention Director Tom Frieden poses the question in a different forum of how we prepare the world for the inevitable next pandemic threat:

Public health systems world-wide need much better tracking systems to sound an early alarm, as well as laboratory networks to find new diseases, detectives to investigate them, rapid-response teams to tackle them, and legal, communication and financial frameworks to make all that possible. We will also need better primary care world-wide to deliver vaccines and manage chronic conditions. As an investment for wealthier countries, international 
organizations, and NGO's, this is a bargain: Every dollar spent on global health security could save $\$ 100$ or more in the costs of future pandemics. Like earthquakes, we know they are coming, even if we don't know where or when. We were caught unprepared this time; that shouldn't happen again. ${ }^{2}$

I was intrigued by the book's title and contend that the public health focus could have been more front and center, with issues critical to those of us on the front lines facing a pandemic: epidemiology and public health, the role of primary care, vaccine distribution and administration, health care financing, access, and health care disparities.

More material from experts like Dr Frieden in health care would have strengthened the book for family doctors interested in the big picture, including geopolitics. In conclusion, this book is a good faith attempt to prognosticate an uncertain post-COVID world from a broad range of well-versed, articulate authors. doi: 10.22454/FamMed.2021.648972

\section{Victor S. Sierpina, MD}

University of Texas Medical Branch - Family

Medicine

Galveston, TX

\section{References}

1. Rutkow L. Origins of the COVID-19 Pandemic and the Path Forward: A Global Public Health Policy Perspective. In: Brands H, Gavin FJ, eds. COVID-19 and World Order Baltimore: Johns Hopkins University Press, 2020: 94-96.

2. Frieden, T. The Vaccine Solution-If We Handle It Right Wall Street Journal, Dec 5-6, 2020: C1-2.

\section{Bloodletting and Germs: A Doctor in Nineteenth Century Rural New York}

Thomas C. Rosenthal

BookBaby (self-published), 2020, 336 pp., \$18.99, paperback

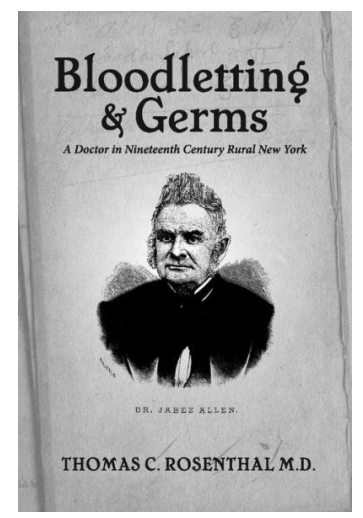

Dr Jabez Allen: Table of Charges (1834)

...Ordinary Home

Visit under one mile: $\$ 1$

Each additional mile: $25 \phi$ (Reduced if feed provided to doctor's horse)
Obstetrics, ordinary, not over 6 hours: $\$ 5$; com-

plicated, $\$ 20 \ldots$

...Venesection (Including Bloodletting, cupping,

blistering). Office: $50 \phi$; in home: $75 \phi$

Application of Leeches: $\$ 2$ per application (may

vary with market and availability)

Vaccination, single patient: $\$ 5$

Pulling a tooth: $50 \varnothing$

Extirpation of tonsils: $\$ 10$

Cutting for bladder stones: $\$ 50$

Removal of fingers or toes: $\$ 1$

Removal of testicle: $\$ 25$

Amputation (Leg, Arm): \$30...

...Pumping stomach: $\$ 5$ (p. 56).

This fictionalized account of the life of a real physician, Dr Jabez Allen, of Aurora, New York, immerses readers into the small-town practice of a young doctor in rural America. If you find the list of fees above entertaining, this book will be well worth your while.

The good doctor Allen arrives at a hotel in Aurora, where he stops for the night on his way to Cincinnati. The locals begin a successful campaign to recruit Dr Allen to build a practice in their town. This well-researched book walks alongside Dr Allen, armed with his newfangled stethoscope, as he finds a shop for his practice, hires an assistant, marries, builds a family, and becomes an integral part of his town. The book alternates between a richly detailed first-person narrative and copious historical asides, tracking the progress of medicine from bloodletting to germs.

This book is worthwhile on many levels. These include knowledge of local and national history, medical history, and the story of the protagonist himself. The author has clearly done a great deal of research into the cultural history of upstate New York in the 19th century. Debates about slavery and abolitionism, the activities of the local Underground Railroad, and the influence of Spiritualists all appear in this narrative. We learn about changes in the local economy wrought by the building of canals and railroads, the move from subsistence to commercial farming, and the influence of coal and steam engines. The section on local sanitation is eye-opening, including accounts of semiferal pigs roaming the streets and eating manure, and latrine and tannery wastes discharging into rivers.

Between culture and medicine reside the ubiquitous quacks and alternative healers, whose influence Dr Allen battles. A colorful character named Phineas J. McCarthy, 
claiming to have a medical degree, appears in town, selling his fraudulent remedy and charming the ladies. Through the efforts of our protagonist, the salesman's lies are exposed, and McCarthy flees town during the night.

The medical history portion is where this book really shines. In Dr Allen's early practice, the primary tools of the physician's trade included frequent purging with bloodletting and with either senna or calomel (a mercury salt with strong laxative properties, $\mathrm{Hg}_{2} \mathrm{Cl}_{2}$, which fortunately does not absorb well into the gastrointestinal tract). The book provides a historical witticism about calomel's explosive effects, "Within the past few days I have passed everything except my hat." Dr Allen describes compounding most of his remedies himself, which is fascinating.

Dr Allen joins the Lake Erie Medical Society, and becomes an active participant. $\mathrm{He}$ acquires up-to-date equipment and keeps up with medical research amazingly well, through reading and participation in professional meetings. A particularly interesting chapter entitled "Germs" (p. 295) chronicles the proceedings of the American Medical Association's 1878 meeting in Buffalo. There ensues a spirited debate between those physicians who believe in germ theory, and those who are reluctant to part with beloved theories about miasmas and moral weakness, intemperance, or an imbalance of humors being the causes of disease. Rosenthal summarizes the results of this contentious conference as follows:

The official minutes simply stated that some members believed germs might eventually explain the occasional epidemic and some inflammations. The committee's output was a resolution much like the previous year's. It recommended streets and homes be kept clean and all households should have access to clean water and nutritious food. (p. 302)

The book suffers from a few weaknesses. It is self-published, and the lack of an editor shows in occasional errors in usage or syntax. Also, the language and concepts can be anachronistic, as for example when the author uses the term "status symbol" (p. 254) before that term was coined.

But all nit-picking aside, the modern language makes the book accessible to the general reader, and the author's love for that era shines through. Bloodletting and Germs is an enjoyable read, full of rich details that make the story compelling. It could serve as a valuable text for a "History of American Medicine" seminar. Most importantly, Dr Rosenthal implicitly invites us to be humble about the current state of our knowledge in medicine, and to nurture the spirit of intellectual curiosity, along with the kindness and generosity, exemplified by Dr Jabez Allen.

doi: 10.22454/FamMed.2021.589184

\section{Esther Strahan, PhD}

St. Rita's Family Medicine Residency

Lima, $\mathrm{OH}$

\section{References}

1. Wikipedia contributors. Calomel. Wikipedia, the Free Encyclopedia. Accessed December 18, 2020. https://en.wikipedia. org/wiki/Calomel. Accessed December 18, 2020.

\section{So Young, So Sad, So Listen: A Parents' Guide to Depression in Children and Young People, 3rd Edition}

Philip Graham, Nick Midgley

Cambridge, UK, Cambridge University Press, 2020, 84 pp., \$9.99, paperback

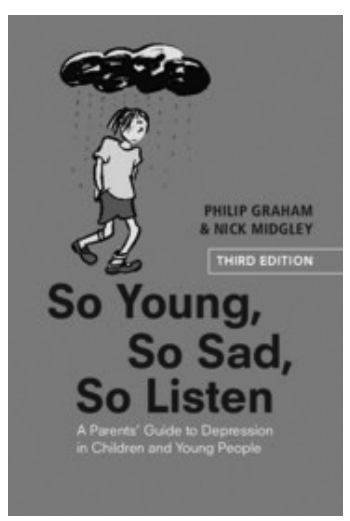

In the United States, an estimated one in six children has a mental, behavioral, or developmental disorder. Even without those diagnoses, millions of young people will experience feelings of depression, stress, or anxiety by the time they reach 18 years of age. ${ }^{1}$ This guide serves to equip parents, teachers, friends, social workers and family doctors (specifically mentioned) with screening and evaluation tools for common mood disorders. Authors Philip Graham and Nick Midgley are child and adolescent psychiatrists and psychotherapists, respectively. As longtime members of the Royal College of Psychiatrists, their collective experience offers a wide breadth of anecdotes, academic knowledge, and clinical pearls.

This concise yet comprehensive book is an excellent resource for anyone involved in the care of children. Teenage angst and moodiness are often attributed to puberty and hormonal changes. It can be very difficult, even for physicians, to distinguish physiologic from pathologic troublesome thoughts. Since depression 
is one of the most common serious diseases in school-aged children (p. 4), the authors present a modified Patient Health Questionnaire (PHQ-9) that encourages parents to be vigilant for new irritability, disturbed sleep, or appetite changes (p. 7).

Unfamiliar with the two previous editions (1995 and 2005), I surmise the sections on social media, screen time, and cyber bullying have been newly added or revised. Nevertheless, the authors still include topics such as physical and verbal abuse, academic pressure, and substance use as issues that have challenged families for decades.

The first few chapters of the guide were the most valuable. The authors describe common symptoms of depression paired with quotes from actual teenagers indicating concerns that could easily be ignored. The example of a 14-year-old child who feels tired all the time and slowly loses interest in previous hobbies (p. 3) serves to remind us that depression isn't simply an unhappy mood, self-harming behavior, or recurring thoughts about death. When a 17-year-old girl states, "I don't exercise as I should; I can't be bothered putting on make-up," an unwitting parent might call this departure from previous behavior a "phase," especially since when asked directly if depressed, this child reported feeling simply "bored".
For an experienced clinician routinely performing a HEADSS (Home, Education/Employment, Activities, Drugs, Sexuality, Suicide) exam at adolescent visits, this guide would predominantly reinforce existing knowledge without much new information. Providers seldom seeing adolescent patients or trainees in family medicine may especially find this guide's content illuminative. Overall, the authors provide practical advice and information about the emotional support and psychological help anyone can give.

doi: 10.22454/FamMed.2021.684119

\section{Arindam Sarkar, MD}

Baylor College of Medicine

Houston, TX

\section{Reference}

1. Cree RA, Bitsko RH, Robinson LR et al. Health care, family, and community factors associated with mental, behavioral, and developmental disorders and poverty among children aged 2-8 years - United States, 2016. MMWR, 2018;67(5):1377-1383.

Reviewers interested in writing reviews for publication should contact Book and Media Reviews Editor William E. Cayley, Jr, MD, at bcayley@yahoo.com.

Publishers who wish to submit books for possible inclusion in Family Medicine's book reviews section should send texts to Sam Grammer, Society of Teachers of Family Medicine, 11400 Tomahawk Creek Parkway, Suite 240, Leawood, KS 66211. fmjournal@stfm.org 